\title{
SOUZA, Gilda de Mello e. O Espírito das Roupas: A Moda no Século XIX. São Paulo: Companhia das Letras, 1987.
}

Fernando Bagiotto Botton ${ }^{1}$

A presente resenha não possui pretensões de trazer novas interpretações da obra de Souza, que é bastante conhecida no meio intelectual da disciplina de sociologia, especialmente quando tratamos das grandes universidades paulistas como a Universidade de São Paulo (USP) e a Universidade Estadual de Campinas (UNICAMP). Porém, pretendemos trazer uma contribuição historiográfica ao propor a leitura de "O Espírito das Roupas" também pelos historiadores, proporcionando uma nova dimensão às discussões de moda e estética, campos em constante crescimento na historiografia da cultura.

Gilda de Mello e Souza (1919-2005) nasceu em São Paulo, ingressou na Faculdade de Filosofia, Ciências e Letras da USP graduando-se em filosofia em 1940, ano em que obteve licenciatura e passou a dar aulas na mesma instituição. Em 1943 foi assistente do sociólogo francês Roger Bastide na cadeira de Sociologia I. Sob a orientação do mesmo, defendeu a tese de doutorado "A moda no

\footnotetext{
${ }^{1}$ Trabalho apresentado quando o autor estava na graduação em História - UFPR.
} 
Século XIX: Ensaio de Sociologia Estética" em Ciências Sociais na USP em 1950.

A tese referida trata-se do mesmo texto aqui resenhado, porém, publicado 37 anos depois da defesa, momento em que a autora recebe o devido reconhecimento. Isso dá elementos para considerarmos esse trabalho "bastante aferente de sua época". É evidente que suas reflexões estavam inseridas no contexto de seu mundo cotidiano, porém, a academia brasileira ainda não enfatizava os estudos culturais, dando preferência aos estudos políticos e econômicos.

Em 1951, ao conseguir publicar um artigo com o mesmo titulo da tese na Revista do Museu Paulista, recebe alguns comentários favoráveis, mas ainda cheios de críticas. Dentre eles está o de Florestan Fernandes:

Poder-se-ia lamentar, porém, a exploração abusiva da liberdade de expressão (a qual não se coaduna com a natureza de um ensaio sociológico) e a falta de fundamentação empírica de algumas das explanações mais sugestivas e importantes. (FERNANDES apud PONTES, 2004, pp. 02)

Através dessa severa crítica mostra-se evidente que a autora foi na contramão de toda a corrente historiográfica e sociológica da época. Segundo a comentadora Heloisa Pontes, é 
possível interpretar algumas nuances dessa crítica de Fernandes. A primeira é de nível estilístico. Souza, antes de entrar para a academia, tentou carreira como escritora ${ }^{2}$, isso lhe rendeu uma fluência particular com o uso das palavras muitas vezes assemelhando suas assertivas a um escrito literário. Essa capacidade, atualmente louvável, foi muito criticada na época da publicação de seu artigo, uma vez que seu estilo de escrita dava às suas publicações "um tom de ensaio". Por isso a crítica de Florestan se mostra tão enfática uma vez que sua preocupação era de consolidar um panorama intelectual que desse à sociologia um potencial de "explicar" os fatos em sua veridicidade, longe da subjetividade e da hermenêutica como nos textos de Souza.

A partir das críticas recebidas pela autora podemos perceber certa tendência a uma abordagem cultural, porém não posso afirmar que ela negue categoricamente a interpretação materialista, embora que tece críticas ao materialismo histórico especialmente o de teor frankfurtiano ${ }^{3}$. Para a autora, há sim um elemento de "fetichização" e "mercadorificação" também na moda, mas isso não afeta seu status de arte ou de passível de ser estudada enquanto uma manifestação cultural.

\footnotetext{
${ }^{2}$ Incentivada por seu primo Mário de Andrade

${ }^{3}$ que considera uma parte das artes do século XX, inclusive a moda, enquanto "indústria cultural"
} 
Por isso, se é possível situar a autora em alguma "corrente historiográfica" me parece coerente inscrevê-la como uma historiadora da cultura. Suas influências são claramente visíveis: citações de Jacob Burkhardt são constantes em sua obra, porem ela parte de uma interpretação mais refinada que a do historiador da cultura do século XIX, muito mais semelhante com a de Carlo Ginzburg. Essa aproximação é comprovada por Otília Beatriz Fiori Arantes:

Há exatamente vinte anos saía o livro do historiador italiano Carlo Ginzburg, "Mitos, emblemas, sinais". Lembro-me de Gilda comentar o quanto se sentiu lisonjeada reencontrando num autor famoso uma explicação erudita de dois métodos de abordagem da obra de arte que lhe eram por assim dizer desde sempre como que congenitamente próprios e que, além do mais, não gozavam de muito prestígio entre os críticos locais, a saber: a arqueologia visual dos mestres da escola de Warburg e o método indiciário praticado pelos connaisseurs, notadamente pelo mais conhecido deles, o médico italiano do século XIX, Giovanni Morelli (ARANTES, 2006, pp.1)

Não que eu me permita analisar a escola de Warburg ou o método indiciário dos connaisseurs, mas essa afirmação mostra a afinidade teórica da autora com o historiador italiano.

Além da presente obra, Souza se concentrou em diversos outros estudos, publicando obras de estética, crítica literária e 
Cadernos de Clio, Curitiba, n. ${ }^{\text {o } 3,2012}$

sociologia como "O tupi e o alaúde: uma interpretação de Macunaíma" (1979), "Exercícios de leitura" (1980) e "A idéia e o figurado" (2005), esse último publicado no ano de sua morte aos 86 anos.

Tratando mais especificamente do livro "O Espírito das Roupas", delinearei alguns detalhes que me pareceram interessantes. A obra, como o próprio nome explica, busca interpretar a moda no século XIX e suas significações sociais.

Sua abordagem é pautada em fontes das mais diversas e próprias, a utilização de pranchas de moda, ilustrações, pinturas e inúmeras fotografias permitem que a autora demonstre ao leitor os detalhes e as configurações da moda no século XIX. Outra metodologia, portadora de muita inovação para a época, é a utilização de trechos literários e testemunhos de romancistas enquanto fontes históricas ou sociológicas. Passagens de José de Alencar, Machado de Assis, Balzac, Proust são magistralmente utilizados para descrever de forma mais detalhada possível as nuances daquela sociedade. Dessa forma, utilizando-se de um extenso e detalhado corpo documental a autora - diferentemente do que afirma Fernandes - faz sim uma rigorosa pesquisa sociológica e histórica ao abordar a moda no século XIX.

No primeiro capítulo, intitulado "A Moda como Arte" a autora lança seus pressupostos teóricos acerca da moda 
Cadernos de Clio, Curitiba, n. ${ }^{\circ}$ 3, 2012

classificando-a como uma arte, com suas próprias nuances e particularidades, que se liga com as outras artes da época, especialmente a arquitetura, a escultura e a pintura, graças à espacialidade, às texturas e às cores em comum. Com isso, baseada no sociólogo e historiador da moda Cunnington, Souza traça os quatro vetores que expressariam a linguagem da moda, a saber: a forma, a cor, o tecido e a mobilidade. Através da articulação desses elementos é possível estabelecer as geometrias estéticas que definiram o belo masculino e o feminino do século XIX, sendo o primeiro definido pela proximidade de aparências a uma letra " $\mathrm{H}$ " onde os ternos, as calças e a sobriedade das roupas lhe dão essa aparência. Já as mulheres cada vez mais se vestiam em um formato semelhante à letra "X", sendo influenciadas pelos vestidos, chapéus e espartilhos. A autora encerra seu capítulo com uma afirmação bastante instigante:

Não é possível estudar uma arte, tão comprometida pelas injunções sociais como é a moda, focalizando-a apenas nos seus elementos estéticos. Para que a possamos compreender em toda sua riqueza, devemos inseri-la no seu momento e no seu tempo, tentando descobrir as ligações ocultas que mantém com a sociedade (SOUZA, 1987, pp. 50-51)

É interessante essa afirmação, pois demonstra uma influência historicista da necessidade de contextualizar 
historicamente a arte "no seu momento e no seu tempo". Outro aspecto interessante é a afirmação de tentar descobrir "as ligações ocultas que mantém com a sociedade": trata-se de interpretar as significações da cultura muito semelhantemente com o que postula Clifford Geertz em sua obra "A Interpretação das Culturas". Segundo ele, a função do antropólogo seria de interpretar a cadeia de significados sociais - passiveis de ser observada através dos diversos signos sociais - de forma a perceber os significados expressos por eles. É uma teorização muito próxima da prática de Souza, me parece ser exatamente uma "descrição densa" que a autora faz no decorrer de seu livro, pois cada traçoldetalhe das roupas, dos comportamentos ou dos sinais sociais são interpretados pela autora que busca "compreender [a sociedade] em toda sua riqueza".

Já no segundo capítulo intitulado "O Antagonismo" a autora se centra na diferenciação sexual ${ }^{4}$ ocorrida no século XIX onde a moda mostrou-se como um dos principais índices de tal separação. Antecipando diversos estudos de gênero feitos atualmente, a autora tratou de forma relacional os modelos de representação da masculinidade e da feminilidade através da significação da vestimenta. Embora mal compreendida pela primeira geração de estudiosas de gênero (décadas de 70 e 80), foi

\footnotetext{
${ }^{4}$ Posteriormente chamada "de gênero"
} 
receber seu devido valor no fim da década de 80 , justamente por abordar os sexos de forma complementar, e não contraditória, em suas palavras "Cada sexo é a imagem dos desejos do sexo oposto [...] Os grupos masculino e feminino acabam se completando. A barreira que os separa não é intransponível". (SOUZA, 1987, pp. 83). Trata-se de uma abordagem de gênero inédita até o final da década de 80 .

Em sua argumentação, a roupa masculina no século XIX foi perdendo todos os traços de exibicionismo centrando-se cada vez mais na seriedade dos tons de preto e cinza. Em completa oposição o traje feminino se enriquece com rendas, enfeites, babados e fitas, perpassando as mais diversas cores, em especial o branco e os tons claros. Refletindo nas próprias nuances daquela sociedade e das distinções de gênero já que os homens incorporavam a seriedade e o ascetismo nessas sóbrias roupas escuras e a mulher incorporava a docilidade da esposa e mãe através das vestimentas claras.

Em seu terceiro capítulo intitulado "A Cultura Feminina", a autora se delonga na moda e nos sinais da vestimenta feminina. Parece-me que é precisamente essa abordagem que fez com que seu estudo tenha sido tão mal aceito pela academia da época e ao

\footnotetext{
${ }^{5}$ Numa evidente referência ao estudo de Georg Simmel que possui o mesmo título.
} 
mesmo tempo com que ele tenha sido editado e reeditado 37 anos depois de sua defesa. Segundo Pontes (2004), na década de 40 a USP ainda estava criando o curso de sociologia que era orientado pela escola francesa. Baseada em modelos estruturalistas e muitas vezes positivistas, buscava atingir uma suposta cientificidade no conhecimento sociológico. Os temas privilegiados eram as grandes estruturas sociais, tirando a prioridade aos aspectos mais peculiares da cultura, como as relações de gênero ou a moda. Já no fím da década de 80 , com a renovação dos "woman studies" sua obra foi reconhecida enquanto portadora de uma refinada análise de gênero. Isso permitiu que seu estudo fosse publicado e que sofresse diversas edições, lançadas até o ano de 2005, sendo que todas já se encontram esgotadas.

Em seu quarto capítulo, intitulado "A Luta das Classes", a autora se opõe à historiografia marxista ortodoxa ao estudar a diferenciação das classes do século XIX não por fatores econômicos, mas por uma peculiaridade cultural: a moda. Outro aspecto de oposição a essa historiografia é com relação a sua interpretação das classes enquanto diversas, maleáveis e portadores de uma "identidade, de usos e costumes, de hábitos e mentalidade" não sendo uma estrutura dicotômica binária exploradoresexplorados. Trata-se, no meu ver, de uma sensibilidade analítica somente proposta posteriormente pela terceira geração da escola dos 
Annales, com sua "História das Mentalidades" ou pela "New Left Revew" de estudos de classe focados por perspectiva cultural.

Outra sensibilidade ímpar da autora foi a de perceber a transitoriedade das influências estéticas da moda entre o meio urbano e o rural. Para a autora, tradicionalmente a sociedade rural não havia se distinguido socialmente através das vestimentas, mas o contato com as elites urbanas proporcionou uma mudança nesse padrão e a sociedade rural passou a adquirir esse "espírito das roupas" que, antes de um princípio estético, servia como um índice de distinção social. Ou melhor, a moda é interpretada por Souza em duas utilidades aparentemente antagônicas, a primeira é que a moda poderia servir como índice de distinção social, mostrando quem tem capacidade e polimento de possuir um traje caro e desconfortável ${ }^{6}$ e ao mesmo tempo a moda poderia aproximar as classes, que agora se vestiam cada vez mais semelhantes, a ponto de muitas vezes serem confundidas graças aos trajes usados.

A autora comenta sobre a reação da nobreza que, ao ver a "confusão" de classes ocasionadas pela vestimenta, se apega em novos distintores sociais como a auto-contenção, a utilização das "boas maneiras", na elaboração dos gestos e no polimento das palavras. Isso dá pressupostos para seu capítulo seguinte, intitulado

\footnotetext{
${ }^{6}$ Apontando que o usuário não labora e tem posses para pagar.
} 
"O Mito da Borralheira". Segundo Souza, talvez baseada em teorias psicanalíticas, comenta que o ascetismo do século XIX precisava encontrar escapes para sua seriedade, talvez o principal deles fosse a festa, local onde as pessoas poderiam, nesse momento de exceção, exaltarem a fantasia e a imaginação. O erotismo era expressado por sutilezas na vestimenta feminina, inspirando os galanteios ou as trocas de olhares e suspiros. É nesse momento de exceção que havia a possibilidade das classes não nobres se inserirem nesse desejado meio, pois o uso apropriado das roupas possibilitava o encontro entre as mais diversas classes em um espaço de sociabilidade comum a todas: os salões. Nesse momento a autora se utiliza da argumentação antropológica para considerar a festa enquanto um ritual de reorganização da sociedade. A expressividade das roupas, unidas aos gestos apropriados, permitiam que em raros momentos houvesse a incorporação de algum membro pela classe alta, possibilitando a reorganização e a permanência das elites pela introdução de novos membros considerados capazes. A boa utilização da moda dentro de uma festa pode-se entender como uma "tática" 7 das classes não nobres, pois isso lhes dá a possibilidade astuta de ascensão social. São aliviadas as tensões sociais graças à possibilidade dos membros das

\footnotetext{
${ }^{7}$ Uso o termo "tática" na concepção de de Certeau (1994) quando o autor se refere à forma astuta de resistência do mais fraco.
} 


\section{Cadernos de Clio, Curitiba, n. ${ }^{\circ}$ 3, 2012}

classes menos nobres de tornarem-se nobres. Não por acaso o capítulo chama-se "O Mito da Borralheira", pois uma vez descidas as cortinas da festa, o rigor do distanciamento entre as classes retornava e a antiga "ordem" social era restabelecida, lançando de volta os considerados "não aptos" das classes não nobres à obscura realidade de seu mundo cotidiano.

A inovação da abordagem e da problemática que essa obra representa é muito expressiva, dado suas opções teóricas e metodológicas. Isso dá um impressionante ar de juventude e contemporaneidade a um trabalho com mais de 50 anos de idade. A erudição da autora pode ser uma chave pela qual alguns comentaristas consideram que "O Espírito das Roupas" conseguiu suspender o tempo e "no lugar de envelhecer, ganhou um frescor e uma atualidade inquietantes" (PONTES, 2004, pp. 10). Trata-se de uma clara demonstração do que Henri-Irenée Marrou quis dizer com: "a riqueza do conhecimento histórico é diretamente proporcional à da cultura pessoal do historiador". A vida intelectual de Souza transparece em uma linguagem fluida e bem direcionada, segundo Alexandre Eulalio o livro "não consegue esconder [...] a sensibilidade literária perspicaz" (EULALIO apud SOUZA, 1987, pp.14). Suas referências: Simone de Beauvoir, Johann Huizinga, Bronislaw Malinowski, Marcel Mauss, Michel de Montaigne, Georg Simmel (todos citados no original) mostram a 
sensibilidade teórica da autora pelas tendências teóricas da época. É uma das formas mais brilhantes de se utilizar de sua bagagem intelectual para escrever uma obra ainda hoje digna de exclamações como as de Pontes: "é uma jóia de ensaio estético e sociológico" (2004, pp. 10).

\section{REFERÊNCIAS}

ARANTES, Otília Beatriz Fiori. Notas sobre o método crítico de Gilda de Mello e Souza. In: Estudos Avançados, São Paulo, v. 20, n. 56, 2006 . Disponível em:

<http://www.scielo.br/scielo.php?script=sci_arttext\&pid=S010340142006000100021\&lng=\&nrm=iso>. Acessado em: 6/11/2008

CERTEAU, Michel De. A invenção do Cotidiano vol.1. Petrópolis: Vozes, 1994.

GEERTZ, Clifford. Uma descrição densa: por uma teoria interpretativa da cultura. In: A Interpretação das Culturas. Rio de Janeiro: Zahar, 1978. Capitulo 1.

MARROU, Henri-Irenée. Sobre o Conhecimento Histórico. Rio de janeiro: Zahar Editores, 1978. 
PONTES, Heloisa. Modas e Modos: uma leitura enviesada de o espírito das roupas. In: Hildete Pereira de Melo, Adriana Piscitelli, Sônia Weidner Maluf, Vera Lucia Puga (organizadoras). Olhares Feministas. Brasília: Ministério da Educação: UNESCO, 2006. 510 p. Retirado de:

<http://unesdoc.unesco.org/images/0015/001545/154563por.pdf> Acessado em: 6/11/2008

A paixão pelas formas: Gilda de Mello e Souza",In: Novos Estudos Cebrap, n.74, março de 2006, pp.-87-105. Retirado de: <http://www.scielo.br/pdf/nec/n74/29641.pdf> Acessado em: $6 / 11 / 2008$

SOUZA, Gilda de Mello e. O Espírito das Roupas: A Moda no Século XIX. São Paulo: Companhia das Letras, 1987. 